\title{
The Role of Granulysin in Cancer Immunology
}

\author{
Satoshi Okada and Tetsuo Morishita \\ Department of Internal Medicine, Ichikawa General Hospital, Tokyo Dental College, 5-11-13 Sugano, Ichikawa 272-8513, Japan \\ Correspondence should be addressed to Satoshi Okada, sokada@tdc.ac.jp
}

Received 4 August 2011; Accepted 2 October 2011

Academic Editors: B. Stijlemans and A. B. Van Spriel

Copyright ( $\odot 2012$ S. Okada and T. Morishita. This is an open access article distributed under the Creative Commons Attribution License, which permits unrestricted use, distribution, and reproduction in any medium, provided the original work is properly cited.

Granulysin is a cytotoxic granule expressed in cytotoxic $\mathrm{T}$ cells and natural killer cells. Although its cytotoxic effect against a number of tumor cell lines has been demonstrated in vitro, recent studies with transgenic mice, and a number of clinical studies, have further established its significance in cancer immunology. Furthermore, granulysin-induced in vitro chemotaxis and activation of both human and mouse dendritic cells have been reported. Given the results in recent clinical studies, granulysin may offer a useful indicator in the prognosis of cancer. Taken together, an understanding of the mechanism by which granulysin destroys target cells would provide vital information in the development of new therapies for the treatment of this disease.

\section{Introduction}

Killer lymphocytes are key players in the effector arm of the immune response, eliminating cells infected by intracellular pathogens and transformed tumor cells [1]. Although T cells and natural killer $(\mathrm{NK})$ cells both destroy their respective targets by the same basic mechanisms, they are triggered by distinct receptors, and the expression of cytotoxic molecules is constitutive in NK cells, but regulated in T cells. Cytotoxic T cells (CTLs) and NK cells can destroy their targets either by releasing cytolytic granules in the granule-exocytosis pathway of cytotoxicity, or by engaging cell-surface death receptors such as members of the tumor necrosis factor receptor (TNFR) family including FAS. Findings in genetically manipulated mice, human genetic diseases, and in vitro studies have indicated that the granule-exocytosis pathway plays the dominant role in eliminating virus-infected cells, processing against intracellular pathogens, and tumor surveillance $[2,3]$. Cytotoxic granules contain a number of molecules such as the pore-forming protein perforin and serine protease granzymes. Granulysin is another cytotoxic molecule colocalizing in the same granules as perforin and granzyme B, and there is a growing body of evidence to suggest that this particular molecule plays an important role in cancer immunology.

\section{Expression and Structure}

Granulysin is expressed in human CTL and NK cells, and its cytotoxicity has been demonstrated in a variety of tumor cell lines and microbes including mycobacterium tuberculosis [4-6]. During immune response, NK cells release granulysin very early, whereas CTLs release it 3-5 days following the activation [7].

Granulysin protein exists in two forms: 9- and 15-kDa [8]. The $15-\mathrm{kDa}$ form is a precursor which is processed into the cytolytic 9-kDa form [9]. The granulysin gene was first identified while searching for $\mathrm{T}$ cell genes late after their activation by subtractive hybridization [10]. Expression of granulysin was demonstrated in activated CD4+, CD8+ $\mathrm{T}$ cells and NK cells [7, 10]. Later, it was shown that gammadelta T cells, CD1-restricted cells, and NKT cells also expressed granulysin $[6,11-14]$. It is a member of the Saposin-like protein family, which includes amoebapores and NK-lysin, and is characterized by a conserved threedimensional structure $[4,15]$. Anderson et al. showed that the crystal structure of this molecule is characterized by a five-helix bundle and is stabilized by two highly conserved intramolecular disulphide bonds, in which it resembles other Saposin-fold proteins. This structure suggests the mechanism by which granulysin functions as a lytic molecule [16]. 
Granulysin homologues have been identified in pig (NKlysin) [17], cow (Bo-lysin) [18], and horse [19]. Although knock out mice were highly informative in defining the function of perforin [2] and granzymes [20], there is no granulysin homolog in mice to date, rendering this approach impossible.

\section{Mechanism of Action}

3.1. Direct Cytotoxicity. An increase in ceramide was first implicated in the underlying mechanism of the cytotoxicity of this molecule [21]. Granulysin-induced apoptosis was associated with an increase in ceramide content and a concomitant decrease in sphingomyelin, suggesting the activation of sphingomyelinases. This finding was obtained in Jurkat cells incubated with $50 \mathrm{uM}$ 9-kDa granulysin for 16 hours. However, 9-kDa granulysin causes cell damage very quickly, suggesting that another mechanism is involved. Kaspar et al. showed that intracellular $\mathrm{Ca} 2+$ was increased in Jurkat cells immediately after treatment with granulysin, which was followed by damage of mitochondria, resulting in loss of electrostatic potential, release of cytochrome c, and activation of casepase-3 [22]. Pardo et al. demonstrated the release of apoptosis-inducing factor (AIF) from mitochondria in granulysin-treated cells [23]. Those studies suggest the involvement of mitochondria in the apoptotic pathway. Okada et al. further investigated the mechanism of $9-\mathrm{kDa}$ granulysin-induced mitochondrial damage. In granulysintreated cells, both cytosolic and intramitochondrial calcium levels increased, followed by a decrease in intracellular potassium level. 9-kDa granulysin-mediated cell death was prevented by both calcium and potassium channel blockers [24]. Granulysin was internalized in target cells and directly damaged mitochondria in the presence of calcium [24]. Overload of intracellular $\mathrm{Ca} 2+$ has long been implicated in the final common pathway in cell death [25]. A decrease in intracellular potassium level has also previously been associated with apoptosis [26, 27]. Physiologic levels of intracellular potassium play a key role in maintaining caspases in their inactive proforms [28]. Loss of intracellular potassium also results in cell shrinkage, which is associated with apoptosis. Furthermore, inhibitors of electron transport, or an increase in cellular glutathione, protected Jurkat cells from granulysin-mediated cell death, strongly suggesting the involvement of reactive oxygen species [24].

The effect of other cytotoxic granules on granulysin-mediated cytotoxicity is another important issue that remained to be elucidated until recently. It is possible that cytotoxicity mediated by cytolytic granules requires a concerted effort by more than one component. Perforin is a pore-forming protein. The original model of perforin-mediated cell death involves homopolymerization in a Ca2+-dependent manner in order to produce pores which then act as channels in the plasma membrane. A high concentration of perforin thus creates pores which subsequently induce cell necrosis. At sublytic concentrations, granzymes enter target cells, leading to apoptosis. However, this widely accepted model is now debated [29]. Granzymes A, B, and H have been shown to enter target cells in the absence of perforin [30-34].
Stenger et al. showed that granulysin was cytotoxic against intracellular mycobacterium tuberculosis in the presence of perforin [5]. However, this finding was challenged [35]. It was shown that granulysin and perforin worked against Jurkat cells in an additive fashion, rather than synergistic manner, suggesting that they function independently [22]. 9-kDa granulysin was also shown to enter Jurkat cells independently of perforin [24]. However, the mechanism of granulysin-mediated cytotoxicity in mammalian cells has only been investigated using 9-kDa recombinant granulysin. Therefore, how granulysin actually works when delivered to target cells through direct interaction with effector cells has remained to be determined until very recent work by Clayberger, Krensky, and their coworkers [36]. They crossed granulysin transgenic (granulysin $(+/-)$ ) mice onto perforinor granzyme B- deficient mice to examine granulysinmediated killing in a more physiologic whole-cell system. Splenocytes from these animals were activated in vitro with IL-15 to generate cytolytic T cells and NK cells. Coculture of effector cells and target cells was done and killing activity of effector cells, mitochondria membrane potential, generation of reactive oxygen species, and activation of caspases were evaluated. They found that granulysin requires perforin, but not granzyme B, to cause apoptosis of target cells. Cytotoxic cell-delivered granulysin induces endoplasmic reticulum stress and activates caspase 7 with, surprisingly, no effect on mitochondria (Figure 1). How does granulysin cause ER stress when it is introduced to target cells through direct interaction between NK cells and target cells? This question remains to be elucidated.

Understanding of mechanism of 9-kDa granulysin is still important because granulysin-derived peptides kill target cells in the same fashion and they are much more potent. 3 uM G8 which is one of those peptides [37] can kill K562 almost completely in 3 hours whereas $9-\mathrm{kDa}$ granulysin needs $30-50 \mathrm{uM}$ concentration to cause cytotoxicity with the same extent (Okada et al. unpublished observation), suggesting it is 10 times more potent than $9-\mathrm{kDa}$ granulysin. Thus granulysin derived peptide could be potential prodrug for cancer therapeutics.

The $15-\mathrm{kDa}$ form was previously believed to be an inactive precursor. However, Chung et al. recently showed in vitro cytotoxic effects even for the $15-\mathrm{kDa}$ granulysin protein obtained from blister fluids in skin lesions of patients with Stevens-Jonson syndrome (SJS) and toxic epidermal necrolysis (TEN) [38]. The $15-\mathrm{kDa}$ form is spontaneously secreted into the cell culture supernatants of NK cell line YT, whereas the $9-\mathrm{kDa}$ form is found only in cell lysates [38].

It should be determined whether $15-\mathrm{kDa}$ granulysininduced cytotoxicity observed in SJS-TEN is caused by direct killing or other mechanism is involved.

3.2. Granulysin Is Chemotactic and Induces Inflammatory Response. It has previously been reported that the $9-\mathrm{kDa}$ recombinant human granulysin could induce migration of human peripheral blood monocytes and mature DCs [39], but not monocyte-derived immature DCs (Mo-iDCs) or murine DCs [39]. However, Tewary et al. have recently observed that both 9 - and $15-\mathrm{kDa}$ granulysin were also 


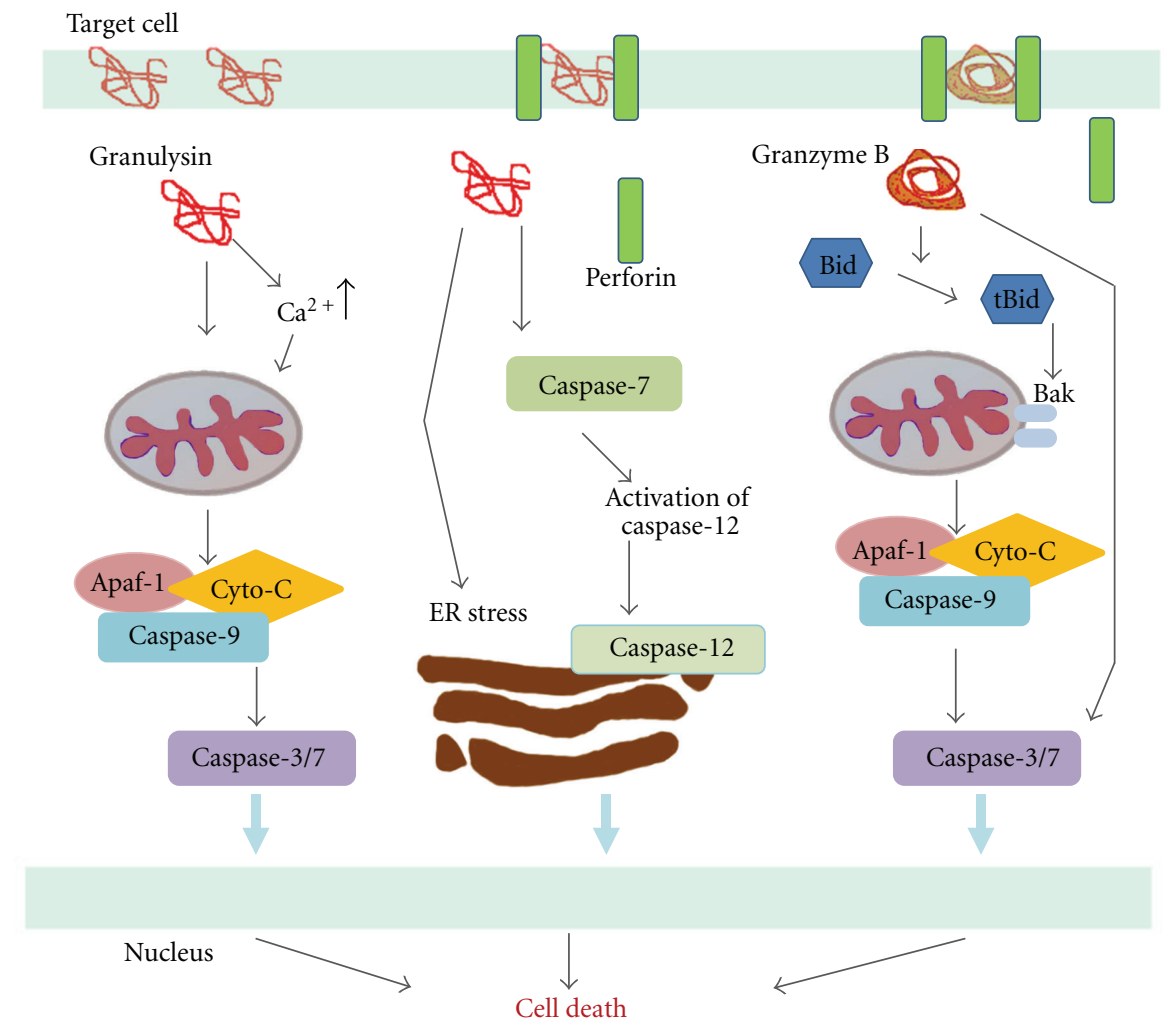

FIGURE 1: Model of apoptosis induced by granulysin or granzyme B. Recombinant 9-kDa granulysin (left panel), cytotoxic celldeliveredgranulysin (middle panel), or cytotoxic cell-delivered granzyme B (right panel) activating different apoptotic pathways. This figure was redrawn with only slight modification based upon a figure which was kindly provided by Drs. Clayberger and Krensky [36], with permission from The Journal of Immunology. Copyright 2011. The American Association of Immunologists, Inc.

able to induce migration of immature Mo-DC in vitro at nanomolar concentrations. This effect was mediated through a Pertussis toxin-sensitive Gi-protein-coupled receptor [40]. They also demonstrated granulysin to be a potent activator of both Mo-DCs and freshly isolated CD1c-positive DCs as evidenced by (1) enhanced expression of costimulatory molecules, (2) augmented cytokine production including IL-6, IL-10, IL-12, and TNF-alpha, and (3) enabling DCs to acquire the capacity to stimulate proliferation of allogeneic lymphocytes in vitro. They also demonstrated that granulysin-mediated recruitment and activation of antigenpresenting cells was dependent on Toll-like receptor 4 [40]. Their findings may have much impact in development of cancer therapeutics. Because of the central role of DCs in coordinating human immunity, and the recognition of a specific immune response to many different cancers, they have received an enormous amount of attention as cancer vaccination adjuvants $[41,42]$.

3.3. In Vivo Model. Although there is a growing body of evidence on the effect of granulysin in vitro, little direct evidence of its effect is yet available. Huang et al. recently demonstrated its effect in vivo in transgenic mice. The transgenic mice were produced using a bacterial artificial chromosome containing the human granulysin gene and its $5^{\prime}$ and $3^{\prime}$ flanking regions. Granulysin $+/-$ mice displayed normal development, fertility, and no abnormal phenotype when housed in a specifically pathogen-free environment. Granulysin was constitutively expressed in NK cells and was expressed in splenocytes at 8-10 days after activation by stimulation of $\mathrm{T}$ cell receptors, showing similar kinetics to those of human peripheral mononuclear cells. C6VL and RMA-S tumor cell lines were used to study the effect of granulysin in vivo. Those cell lines were injected i.p. in mice, and survival was monitored daily for at least 60 days. Transgenic mice exhibited an enhanced in vivo response against $\mathrm{T}$ lymphoma C6VL compared with littermates, leading to improved tumor rejection and longer survival [43]. This study provided the first direct evidence that granulysin functioned in vivo to enhance tumor immunity.

\section{Clinical Relevance}

Tumor-infiltrating lymphocytes have been demonstrated to be quite significant in human colorectal cancer. The host showed a higher survival rate when the cancer tissue showed infiltration of inflammatory cells, and lymphocytic reactions in particular [44]. Pagès et al. investigated the role of tumorinfiltrating immune cells in the early metastatic invasion of colorectal cancer. They performed real-time PCR in 75 tissue samples obtained from patients who underwent primary resection. They demonstrated that upregulated granulysin 
mRNA expression at the tumor site was associated with a favorable outcome in patients with colorectal cancer [45]. Kishi et al. demonstrated a correlation between granulysin expression and clinical outcome in patients with cancer. Progression of cancer was associated with decreased granulysin expression in peripheral NK cells in controls and tumor-free patients. In contrast, perforin expression was similar in all three groups. Granulysin may offer a useful prognostic indicator in the development of effective tumor therapy [46]. Saigusa et al. measured preoperative serum granulysin concentration in patients with gastric carcinoma and in healthy controls and assessed its prognostic value. They demonstrated that serum granulysin levels in 87 patients with gastric carcinoma were significantly higher (particularly in patients with stage II and III disease) than in healthy controls. In contrast, serum granulysin levels were significantly lower in patients with stage IV carcinoma than in controls. They concluded that preoperative serum granulysin level reflected status of cell-mediated immunity in patients with gastric carcinoma, and that, therefore, it was significant as a prognostic determinant [47]. Sekiya et al. expressed 9-kDa granulysin in a small cell lung cancer model in mice using an adenovirus vector and found that it induced apoptosis in tumor cells [48]. Yi et al., likewise, expressed 9$\mathrm{kDa}$ granulysin intracellularly in hepatoma cell line SMMC7721, causing apoptosis [49]. Those studies may suggest potential use of 9-kDa granulysin in gene therapy for cancer. Wang et al. showed that synthetic peptides derived from the central region of granulysin were cytotoxic against Jurkat cells as well as Pseudomonas aeruginosa [37]. Some of those peptides were much more effective in killing mammalian target cells, as described above, when they were coincubated with cells or expressed intracellularly.

\section{Conclusion}

The results of recent laboratory studies, especially those using transgenic mice, and clinical studies suggest that granulysin is a key player in cancer immunology. Furthermore, recent finding in granulysin-mediated cytotoxicity and other important roles as a chemoattractant and a stimulator of DCs may guide us to novel therapeutics to treat cancers.

\section{Abbreviations}

NK: natural killer,

CTL: $\quad$ cytotoxic T cell,

TNFR: tumor necrosis factor receptor,

AIF: apoptosis inducing factor,

ER: endoplasmic reticulum,

SJS: $\quad$ Stevens-Jonson syndrome,

TEN: toxic epidermal necrolysis,

DC: dendritic cell,

Mo-iDC: monocyte derived immature DC.

\section{References}

[1] J. H. Russell and T. J. Ley, "Lymphocyte-mediated cytotoxicity," Annual Review of Immunology, vol. 20, pp. 323-370, 2002.
[2] D. Kagi, B. Ledermann, K. Burki et al., "Cytotoxicity mediated by $\mathrm{T}$ cells and natural killer cells is greatly impaired in perforin-deficient mice," Nature, vol. 369, no. 6475, pp. 31-37, 1994.

[3] S. Balkow, A. Kersten, T. T. T. Tran et al., "Concerted action of the FasL/Fas and perforin/granzyme A and B pathways is mandatory for the development of early viral hepatitis but not for recovery from viral infection," Journal of Virology, vol. 75, no. 18, pp. 8781-8791, 2001.

[4] C. Clayberger and A. M. Krensky, "Granulysin," Current Opinion in Immunology, vol. 15, no. 5, pp. 560-565, 2003.

[5] S. Stenger, D. A. Hanson, R. Teitelbaum et al., "An antimicrobial activity of cytolytic T cells mediated by granulysin," Science, vol. 282, no. 5386, pp. 121-125, 1998.

[6] S. Stenger, J. P. Rosat, B. R. Bloom, A. M. Krensky, and R. L. Modlin, "Granulysin: a lethal weapon of cytolytic T cells," Immunology Today, vol. 20, no. 9, pp. 390-394, 1999.

[7] S. V. Peña, D. A. Hanson, B. A. Carr, T. J. Goralski, and A. M. Krensky, "Processing, subcellular localization, and function of 519 (granulysin), a human late T cell activation molecule with homology to small, lytic, granule proteins," The Journal of Immunology, vol. 158, no. 6, pp. 2680-2688, 1997.

[8] W. C. Manning, S. O’Farrell, T. J. Goralski, and A. M. Krensky, "Genomic structure and alternative splicing of 519, a gene expressed late after T cell activation," The Journal of Immunology, vol. 148, no. 12, pp. 4036-4042, 1992.

[9] D. A. Hanson, A. A. Kaspar, F. R. Poulain, and A. M. Krensky, "Biosynthesis of granulysin, a novel cytolytic molecule," Molecular Immunology, vol. 36, no. 7, pp. 413-422, 1999.

[10] J. Jongstra, T. J. Schall, and B. J. Dyer, "The isolation and sequence of a novel gene from a human functional T cell line," The Journal of Experimental Medicine, vol. 165, no. 3, pp. 601614, 1987.

[11] L. Mincheva-Nilsson, O. Nagaeva, K. G. Sundqvist, M. L. Hammarström, S. Hammarström, and V. Baranov, " $\gamma \delta$ T cells of human early pregnancy decidua: evidence for cytotoxic potency," International Immunology, vol. 12, no. 5, pp. 585596, 2000.

[12] F. M. Spada, E. P. Grant, P. J. Peters et al., "Self-recognition of CD1 by $\gamma / \delta$ T cells: implications for innate immunity," The Journal of Experimental Medicine, vol. 191, no. 6, pp. 937-948, 2000.

[13] F. Dieli, M. Troye-Blomberg, J. Ivanyi et al., "Granulysindependent killing of intracellular and extracellular Mycobacterium tuberculosis by $\mathrm{V}-\gamma 9 / \mathrm{V} \delta 2 \mathrm{~T}$ lymphocytes," Journal of Infectious Diseases, vol. 184, no. 8, pp. 1082-1085, 2001.

[14] J. L. Gansert, V. Kießler, M. Engele et al., "Human NKT cells express granulysin and exhibit antimycobacterial activity," The Journal of Immunology, vol. 170, no. 6, pp. 3154-3161, 2003.

[15] R. S. Munford, P. O. Sheppard, and P. J. O'Hara, “Saposin-like proteins (SAPLIP) carry out diverse functions on a common backbone structure," Journal of Lipid Research, vol. 36, no. 8, pp. 1653-1663, 1995.

[16] D. H. Anderson, M. R. Sawaya, D. Cascio et al., "Granulysin crystal structure and a structure-derived lytic mechanism," Journal of Molecular Biology, vol. 325, no. 2, pp. 355-365, 2003.

[17] M. Andersson, H. Gunne, B. Agerberth et al., "NK-lysin, a novel effector peptide of cytotoxic T and NK cells. Structure and cDNA cloning of the porcine form, induction by interleukin 2, antibacterial and antitumour activity," The EMBO Journal, vol. 14, no. 8, pp. 1615-1625, 1995.

[18] J. J. Endsley, J. L. Furrer, M. A. Endsley et al., "Characterization of bovine homologues of granulysin and NK-lysin," The Journal of Immunology, vol. 173, no. 4, pp. 2607-2614, 2004. 
[19] E. G. Davis, Y. Sang, B. Rush, G. Zhang, and F. Blecha, "Molecular cloning and characterization of equine NK-lysin," Veterinary Immunology and Immunopathology, vol. 105, no. 12, pp. 163-169, 2005.

[20] J. W. Heusel, R. L. Wesselschmidt, S. Shresta, J. H. Russell, and T. J. Ley, "Cytotoxic lymphocytes require granzyme B for the rapid induction of DNA fragmentation and apoptosis in allogeneic target cells," Cell, vol. 76, no. 6, pp. 977-987, 1994.

[21] S. Gamen, D. A. Hanson, A. Kaspar, J. Naval, A. M. Krensky, and A. Anel, "Granulysin-induced apoptosis. I. Involvement of at least two distinct pathways," The Journal of Immunology, vol. 161, no. 4, pp. 1758-1764, 1998.

[22] A. A. Kaspar, S. Okada, J. Kumar et al., "A distinct pathway of cell-mediated apoptosis initiated by Granulysin," The Journal of Immunology, vol. 167, no. 1, pp. 350-356, 2001.

[23] J. Pardo, P. Pérez-Galán, S. Gamen et al., "A role of the mitochondrial apoptosis-inducing factor in granulysin-induced apoptosis," The Journal of Immunology, vol. 167, no. 3, pp. 1222-1229, 2001.

[24] S. Okada, Q. Li, J. C. Whitin, C. Clayberger, and A. M. Krensky, "Intracellular mediators of granulysin-induced cell death," The Journal of Immunology, vol. 171, no. 5, pp. 2556-2562, 2003.

[25] F. A. X. Schanne, A. B. Kane, E. E. Young, and F. L. Farber, "Calcium dependence of toxic cell death: a final common pathway," Science, vol. 206, no. 4419, pp. 700-702, 1979.

[26] I. Vermes, C. Haanen, H. Steffens-Nakken, and C. Reutelingsperger, "A novel assay for apoptosis. Flow cytometric detection of phosphatidylserine expression on early apoptotic cells using fluorescein labelled Annexin V," Journal of Immunological Methods, vol. 184, no. 1, pp. 39-51, 1995.

[27] H. Repp, H. Nieper, H. J. Draheim, A. Koschinski, H. Müller, and F. Dreyer, "Infectious bursal disease virus changes the potassium current properties of chicken embryo fibroblasts," Virology, vol. 246, no. 2, pp. 362-369, 1998.

[28] F. M. Hughes Jr. and J. A. Cidlowski, "Potassium is a critical regulator of apoptotic enzymes in vitro and in vivo," Advances in Enzyme Regulation, vol. 39, pp. 157-171, 1999.

[29] M. Barry and R. C. Bleackley, "Cytotoxic T lymphocytes: all roads lead to death," Nature Reviews Immunology, vol. 2, no. 6, pp. 401-409, 2002.

[30] K. M. Edwards, C. M. Kam, J. C. Powers, and J. A. Trapani, "The human cytotoxic $\mathrm{T}$ cell granule serine protease granzyme $\mathrm{H}$ has chymotrypsin-like (chymase) activity and is taken up into cytoplasmic vesicles reminiscent of granzyme Bcontaining endosomes," Journal of Biological Chemistry, vol. 274, no. 43, pp. 30468-30473, 1999.

[31] C. J. Froelich, K. Orth, J. Turbov et al., "New paradigm for lymphocyte granule-mediated cytotoxicity: target cells bind and internalize granzyme $\mathrm{B}$, but an endosomolytic agent is necessary for cytosolic delivery and subsequent apoptosis," Journal of Biological Chemistry, vol. 271, no. 46, pp. 2907329079, 1996.

[32] D. A. Jans, L. J. Briggs, P. Jans et al., "Nuclear targeting of the serine protease granzyme A (fragmentin-1)," Journal of Cell Science, vol. 111, no. 17, pp. 2645-2654, 1998.

[33] M. J. Pinkoski, M. Hobman, J. A. Heibein et al., "Entry and trafficking of granzyme B in target cells during granzyme Bperforin-mediated apoptosis," Blood, vol. 92, no. 3, pp. 10441054, 1998.

[34] L. Shi, S. Mai, S. Israels, K. Browne, J. A. Trapani, and A. H. Greenberg, "Granzyme B (GraB) autonomously crosses the cell membrane and perforin initiates apoptosis and GraB nuclear localization," The Journal of Experimental Medicine, vol. 185 , no. 5, pp. 855-866, 1997.

[35] D. H. Canaday, R. J. Wilkinson, Q. Li, C. V. Harding, R. F. Silver, and W. H. Boom, "CD4 $4^{+}$and $\mathrm{CD} 8^{+}$T cells kill intracellular Mycobacterium tuberculosis by a perforin and Fas/Fas ligand-independent mechanism," The Journal of Immunology, vol. 167, no. 5, pp. 2734-2742, 2001.

[36] R. V. Saini, C. Wilson, M. W. Finn, T. Wang, A. M. Krensky, and C. Clayberger, "Granulysin delivered by cytotoxic cells damages endoplasmic reticulum and activates caspase-7 in target cells," The Journal of Immunology, vol. 186, no. 6, pp. 3497-3504, 2011.

[37] Z. Wang, E. Choice, A. Kaspar et al., "Bactericidal and tumoricidal activities of synthetic peptides derived from granulysin," The Journal of Immunology, vol. 165, no. 3, pp. 14861490, 2000.

[38] W. H. Chung, S. I. Hung, J. Y. Yang et al., "Granulysin is a key mediator for disseminated keratinocyte death in StevensJohnson syndrome and toxic epidermal necrolysis," Nature Medicine, vol. 14, no. 12, pp. 1343-1350, 2008.

[39] A. Deng, S. Chen, Q. Li, S. C. Lyu, C. Clayberger, and A. M. Krensky, "Granulysin, a cytolytic molecule, is also a chemoattractant and proinflammatory activator," The Journal of Immunology, vol. 174, no. 9, pp. 5243-5248, 2005.

[40] P. Tewary, D. Yang, G. De La Rosa et al., "Granulysin activates antigen-presenting cells through TLR4 and acts as an immune alarmin," Blood, vol. 116, no. 18, pp. 3465-3474, 2010.

[41] C. J. Turtle and D. N. J. Hart, "Dendritic cell biology and application for tumour immunotherapy," Cancer Forum, vol. 26, no. 2, pp. 109-112, 2002.

[42] J. A. López and D. N. J. Hart, "Current issues in dendritic cell cancer immunotherapy," Current Opinion in Molecular Therapeutics, vol. 4, no. 1, pp. 54-63, 2002.

[43] L. P. Huang, S. C. Lyu, C. Clayberger, and A. M. Krensky, "Granulysin-mediated tumor rejection in transgenic mice," The Journal of Immunology, vol. 178, no. 1, pp. 77-84, 2007.

[44] H. Ohtani, "Focus on TILs: prognostic significance of tumor infiltrating lymphocytes in human colorectal cancer.," Cancer Immunity, vol. 7, p. 4, 2007.

[45] F. Pagès, A. Berger, M. Camus et al., "Effector memory T cells, early metastasis, and survival in colorectal cancer," The New England Journal of Medicine, vol. 353, no. 25, pp. 2654-2666, 2005.

[46] A. Kishi, Y. Takamori, K. Ogawa et al., "Differential expression of granulysin and perforin by NK cells in cancer patients and correlation of impaired granulysin expression with progression of cancer," Cancer Immunology, Immunotherapy, vol. 50, no. 11, pp. 604-614, 2001.

[47] S. Saigusa, T. Ichikura, H. Tsujimoto et al., "Serum granulysin level as a novel prognostic marker in patients with gastric carcinoma," Journal of Gastroenterology and Hepatology, vol. 22, no. 8, pp. 1322-1327, 2007.

[48] M. Sekiya, A. Ohwada, M. Katae, T. Dambara, I. Nagaoka, and Y. Fukuchi, "Adenovirus vector-mediated transfer of 9 $\mathrm{kDa}$ granulysin induces DNA fragmentation in $\mathrm{HuD}$ antigenexpressing small cell lung cancer murine model cells," Respirology, vol. 7, no. 1, pp. 29-35, 2002.

[49] Z. Yi, Y. Fu, G. Jin, M. Li, X. Zhang, and W. Song, "Intracellularly expressed granulysin induced apoptosis in hepatoma cells and role of mitochondrial apoptotic pathway," Cellular Immunology, vol. 255, no. 1-2, pp. 76-81, 2009. 


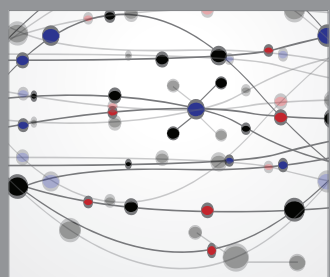

The Scientific World Journal
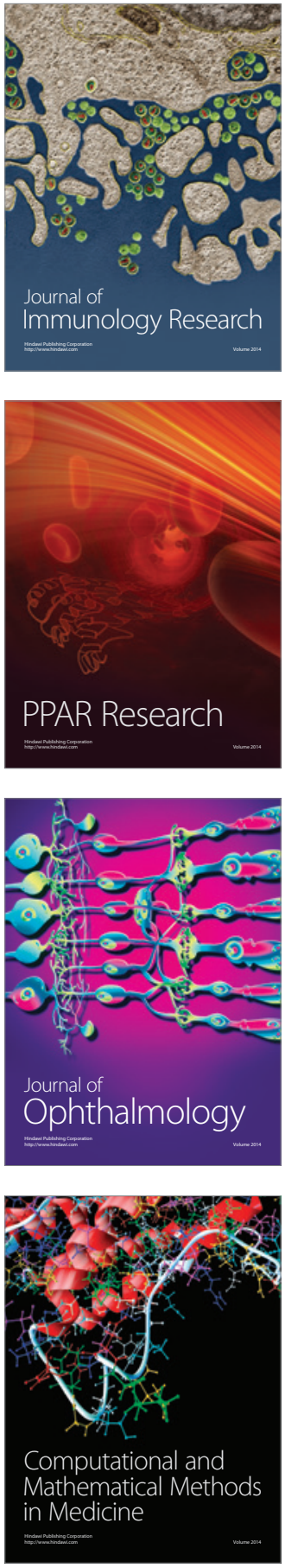

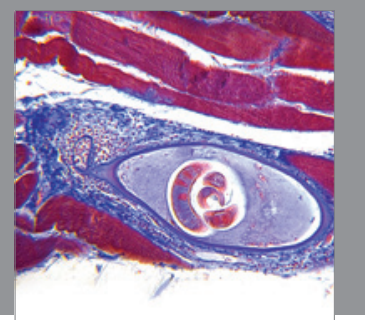

Gastroenterology

Research and Practice
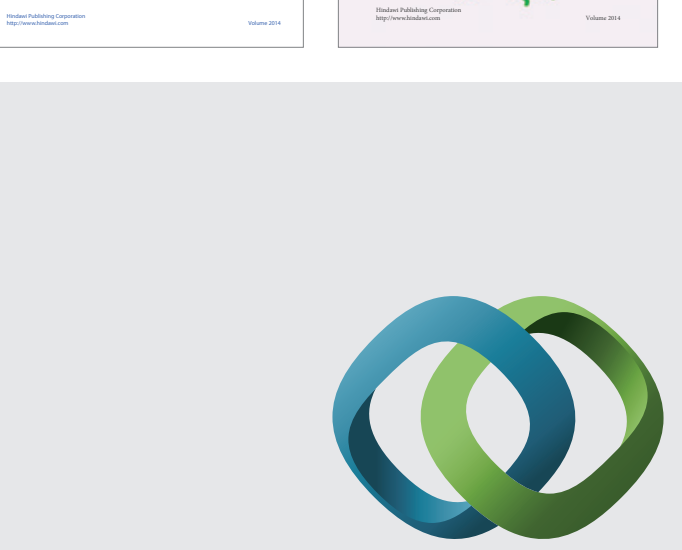

\section{Hindawi}

Submit your manuscripts at

http://www.hindawi.com
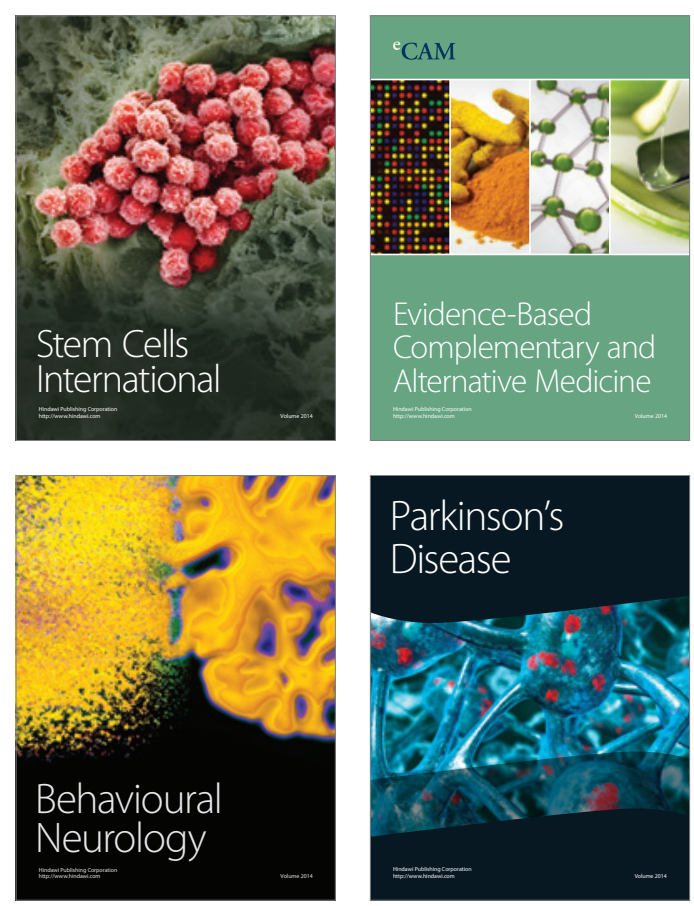

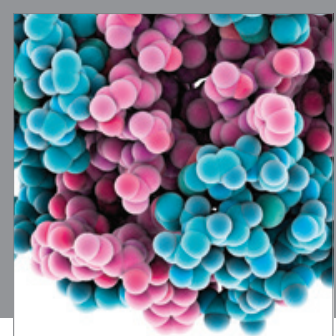

Journal of
Diabetes Research

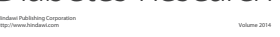

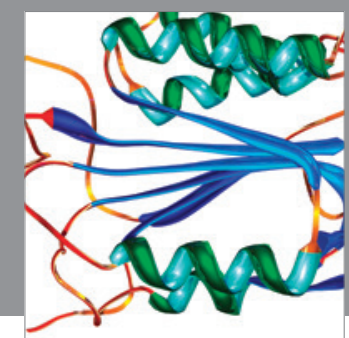

Disease Markers
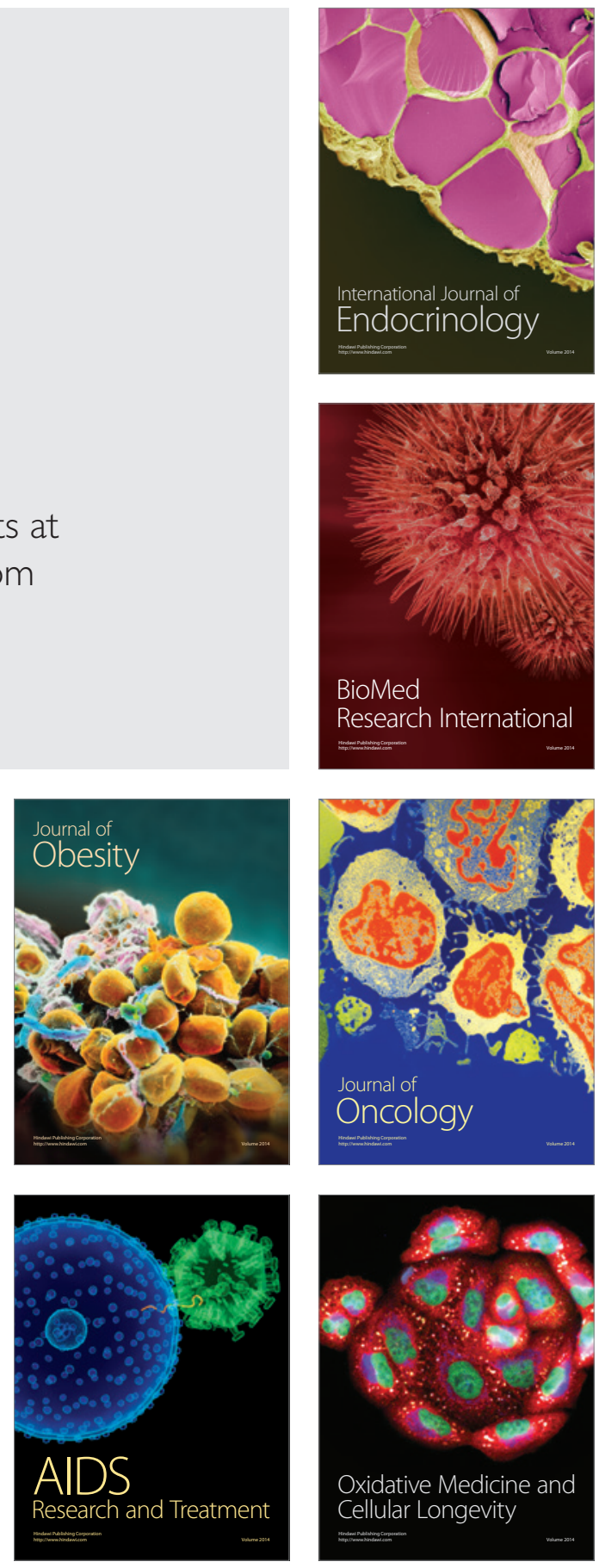